\title{
Un Grec du Nord
}

\section{Thomas Mohnike et Jesper Svenbro}

Traducteur : Emmanuel Curtil

\section{(2) OpenEdition}

\section{Journals}

Édition électronique

URL : https://journals.openedition.org/rbnu/2017

DOI : 10.4000/rbnu. 2017

ISSN : 2679-6104

\section{Éditeur}

Bibliothèque nationale et universitaire de Strasbourg

\section{Édition imprimée}

Date de publication : 1 novembre 2013

Pagination : 66-69

ISBN : 9782859230517

ISSN : 2109-2761

\section{Référence électronique}

Thomas Mohnike et Jesper Svenbro, "Un Grec du Nord », La Revue de la BNU [En ligne], 8 | 2013, mis en ligne le 01 novembre 2013, consulté le 21 mai 2021. URL : http://journals.openedition.org/rbnu/ 2017 ; DOI : https://doi.org/10.4000/rbnu.2017

\section{c) (1) (2)}

La Revue de la BNU est mise à disposition selon les termes de la Licence Creative Commons Attribution - Pas d'Utilisation Commerciale - Partage dans les Mêmes Conditions 4.0 International. 


\section{UN GREG DU NORD}

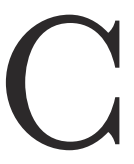

omment décrire la poésie de Jesper Svenbro ? Comment le décrire lui-même ? Poète suédois, de cœur français et d'inspiration hellénique? Européen métapoétique ? Né en 1944 dans le Grand Sud de la Suède, il est spécialiste de littérature grecque ancienne, directeur de recherche au CNRS à Paris et, depuis 2006, membre de l'Académie suédoise. Comme chercheur, il utilise souvent la langue française pour écrire sur l'origine de la poésie grecque ( $L a$ Parole et le marbre: aux origines de la poétique grecque, 1976) et la façon dont les anciens Grecs ont pratiqué l'activité que nous appelons " lire" (Phrasikleia : anthropologie de la lecture en Grèce ancienne, 1988). Depuis 1966, il publie aussi des recueils de poèmes en langue suédoise, qui couvrent la géographie européenne du sud au nord, créant des liens entre les littératures, langues et expériences de tout ce continent et discutant des conditions de production et d'existence de la poésie. Parmi ces nombreuses escalades poétiques, je voudrais mentionner avant tout la suite de poèmes Samisk Apollon och andra dikter (Apollon samien et autres poèmes), publiée en 1993, qui fut ma première rencontre avec le poète et dont nous publions ici deux inédits avec leurs traductions françaises. Le poète y retrouve, souvent accompagné par Arthur Rimbaud dans son voyage lyrique, les dieux et les mythes grecs dans le paysage de la Laponie.
Sous sa plume, les montagnes du Grand Nord de la Scandinavie se transforment en Olympe - pas forcément en raison d'un lien historique caché, mais plutôt à la faveur d'un jeu sur les mots : le nom «Apollon samien " renvoie d'abord au dieu grec sous la forme qu'il a prise pour les habitants de l'île de Samos. En même temps, le mot " samisk " signifie en suédois tout qui renvoie aux cultures des habitants de la Laponie, les peuples sames. Les deux poèmes que nous publions ici sont donc exemplaires quant au pouvoir qu'a la poésie de créer des réalités, d'établir des liens, des réseaux d'images et de se jouer de la géographie - qui pourrait après la lecture de ces poèmes encore voyager dans les pays du Nord sans penser à Apollon?

\section{Thomas Mohnike}




\section{JOJK}

Nu står jag här vid Raurejokk och jojkar min gamla jojk från förr i världen, jojken jag lärde mig av Homeros Blind, som kunde många jojkar och som vaktat många hjordar. Hos många renägare hade han tjänat, men längesen var det naja vaja vaja. Hos många rika lappar hade han varit dräng och vaktat deras hjordar hade han mindre renhjordar och större renhjordar i de vidsträckta beteslanden ovanför björkskogen. Och vargen var hans bästa vän. Hur kunde vargen bli hans bästa vän när han var lappdräng under Ammarfjället? Hur kunde stavens man, med jaktspjutet $\mathrm{i}$ handen, bli vargens bästa vän? Naja vaja vaja. Fattig var han, hade inga egna renar men fick vakta renhjordar åt andra. Så vargen blev hans bästa vän: den höjde ju hans lön, höjde hans lön när den sprang genom dalarna, sprang och sprang. Och nog hände det att den rev en stor och vacker rentjur, som lämnat de andra och gått för sig själv och länge varit ensam på fjället: det blev belöningen för att den höjt hans lön. För vargen fick riva den, rev den och åt: blodig var den kring käftarna, blodig i raggen, och sprang ned till den outtömliga källan, drack sig otörstig där, drack med slaskande tunga i mörka skimrande kallkällan under björkarna, spottade blod i det virvlande vattnet. Naja vaja vaja, den drack och den drack. Nog var den allt hans bästa vän.

\section{YOÏK}

Face au Raurejokk je chante mon yoïk, mon vieux yoïk des temps passés, yoïk que j'ai appris d'Homère Blind, littéralement «l'Aveugle », qui connaissait tant de yoïks et avait gardé tant de troupeaux. Il avait travaillé chez nombre d'éleveurs de rennes, mais depuis longtemps déjà, c'était : naïa vaïa vaïa. Employé par tant de riches Sames, il avait gardé leurs troupeaux, leurs petits et grands troupeaux de rennes, dans les vastes prés qui surplombent la forêt de bouleaux. Le loup était son meilleur ami.

Mais comment le loup pouvait-il être le meilleur ami d'un gardien de troupeaux au pied de l'Ammarfjället ? Comment le berger, lance de chasse à la main, pouvait-il être le meilleur ami du loup ? Naïa vaïa vaïa. Il était pauvre, ne possédait aucun renne, mais devait garder les rennes des autres. Alors le loup est devenu son meilleur ami : lui assurant de plus hauts revenus ; oui, de plus hauts revenus en courant, courant, courant à travers vaux et vallées. Alors un jour, le loup put tuer un magnifique renne qui avait quitté le troupeau pour aller seul, un renne depuis longtemps seul sur la montagne : ce renne était le salaire de la hausse du salaire du berger. Il obtint le droit de le tuer, alors il le tua et le dévora : la gueule pleine de sang, le pelage plein de sang, il gagna son inépuisable source où il étancha sa soif, lapant l'eau de la source froide et scintillante cachée sous les bouleaux, crachant du sang dans l'onde tourbillonnante.

Naïa vaïa vaïa, il but et but encore.

Il était vraiment son meilleur ami. 


\section{WASSERFALL}

Också Rimbaud begav sig en dag "åt norr-hållet", Nor-wège, med denna ålderdomliga stavning,

"Norge" i etymologisk bemärkelse, med dess vindar och fjäll, med dess fjordar långt bortom Ossians hav i seklets mycket mytiska geografi.

På honom tänkte vi i det ögonblick Sveriges Riksdag tog beslutet mot Vindelälvens exploatering och Helikon räddades: tu vates eris, "du ska en dag bli nåjd", hade Apollon sagt honom medan solen gick upp över myrar och sjöar och fick högfjällets snöfält att brinna.

Och nog blev han nåjd i detta nordliga Etiopien, nåjd på kalfjället där hans himlar var lika blå som dem vi såg i vår egen tid, hans jojkande gav oss ledning när vi blev varse Gudinnan, spåren av hennes silverfot där hon upplösts i dimman på vår doftande äng. I flera år trodde vi att Tjulträskets vattennivå skulle höjas med 18 meter, att Rödingvik och Dårraudden skulle försvinna i djupet, vi trodde att vi var de sista som fick se vad vi såg: en fjällvärld illuminerad av regnbågen där varje blomma sa oss sitt namn. Je ris au wasserfall, "jag skrattade åt Vattenfall", fastställde då en uppsluppen röst: året var 1970 och Skådaren hade fått rätt, han hade sett in $\mathrm{i}$ framtiden, tänker jag och skrattar mot vattenfallet där Raurejokk störtar huvudstupa ned genom skogen, brushuvudstupa ned bland stenblock och björkar i ravinen ovanför Rödingvik. 


\section{WASSERFALL}

Rimbaud prit un jour lui aussi le « chemin du Nord », Nor-wège dans son ancienne graphie, la Norvège dans son sens étymologique, avec ses vents, ses montagnes et ses fjords, bien au-delà des mers d'Ossian selon la géographie très mythique de son siècle. Notre pensée alla vers lui le jour où le Parlement suédois adopta la résolution contre l'exploitation hydroélectrique de Vindelälven et où le Vindelfjäll, littéralement l'Hélicon, fut sauvé : tu vates eris ${ }^{1}$, " un jour tu seras voyant », lui avait annoncé Apollon alors que le soleil se levait au-dessus des marais et des lacs, embrasant les neiges de la haute montagne.

Et il devint voyant en cette Éthiopie septentrionale ${ }^{2}$, en devenant noaidi dans la toundra où les cieux étaient aussi bleus que ceux que nous voyions alors c'étaient ses yoïks ${ }^{3}$ qui nous guidaient lorsque nous vîmes la Déesse, la trace de son pied d'argent, là où elle s'était évaporée dans les brumes de notre pré parfumé. Pendant des années nous avons cru que le niveau du lac Tjulträsk allait monter de 18 mètres et que Rödingvik et Dårraudden allaient disparaître dans les profondeurs, nous avons cru être les derniers à voir ce que nous avions vu : une montagne illuminée par l'arc-en-ciel où chaque fleur nous disait son nom. Je ris au wasserfall, en suédois " jag skrattade åt Vattenfall » ${ }^{4}$ affirma alors une voix hilare :

nous étions en 1970 et le Voyant avait eu raison, il avait vu clair dans l'avenir, pensé-je en riant devant la chute d'eau où Raurejokk se précipite la tête la première à travers la forêt, se déversant entre bouleaux et blocs de pierres dans le ravin qui surplombe Rödingvik.

\section{Traduction française} d'Emmanuel Curtil

\section{Notes}

\footnotetext{
1 - Le latin " vates " (voyant, poète visionnaire) se traduit " nåjd » en langue same, soit " noaidi ". Tu vates eris, citation d'un poème latin de l'écolier Rimbaud, âgé de 10 ans, non sans rapport avec la célèbre « Lettre du voyant".

2 - Pour une pensée géographique ancienne, les Éthiopiens ou « Visages brûlés " ont un répondant symétrique dans le Grand Nord, les Sames ayant eux aussi, pour preuve, le teint foncé.

3 - Chants traditionnels des peuples sames.

4 - Vattenfall est l'entreprise nationale de production et de distribution d'électricité en Suède. Son nom signifie " chute d'eau ».
} 